\title{
BIOFILM FORMATION BY STAPHYLOCOCCI ON FRESH, FRESH-FROZEN AND PROCESSED HUMAN AND BOVINE BONE GRAFTS
}

\author{
Martin Clauss ${ }^{1,2, *}$, Ulrika Furustrand Tafin ${ }^{2}$, Alain Bizzini ${ }^{2}$, Andrej Trampuz ${ }^{2}$ and Thomas Ilchmann ${ }^{1}$ \\ ${ }^{1}$ Clinic for Orthopaedic and Trauma Surgery, Kantonsspital Baselland Liestal, Liestal, Switzerland \\ ${ }^{2}$ Infectious Diseases Service, Department of Medicine, University Hospital Lausanne (CHUV), \\ Lausanne, Switzerland
}

\begin{abstract}
Biofilm formation is a multi-step process influenced by surface properties. We investigated early and mature biofilm of Staphylococcus aureus on 4 different biological calcium phosphate $(\mathrm{CaP})$ bone grafts used for filling bone defects. We investigated standardised cylinders of fresh and fresh-frozen human bone grafts were harvested from femoral heads; processed human and bovine bone grafts were obtained preformed. Biofilm formation was done in tryptic soy broth (TSB) using S. aureus (ATCC 29213) with static conditions. Biofilm density after $3 \mathrm{~h}$ (early biofilm) and $24 \mathrm{~h}$ (mature biofilm) was investigated by sonication and microcalorimetry. After $3 \mathrm{~h}$, bacterial density was highest on fresh-frozen and fresh bone grafts. After $24 \mathrm{~h}$, biofilm density was lowest on fresh bone grafts $(p<0.001)$ compared to the other 3 materials, which did not differ quantitatively $(p>0.05)$. The lowest increase in bacterial density was detected on fresh bone grafts $(p<0.001)$. Despite normal shaped colonies, we found additional small colonies on the surface of the fresh and fresh-frozen samples by sonication. This was also apparent in microcalorimetric heat-flow curves. The four investigated $\mathrm{CaP}$ bone grafts showed minor structural differences in architecture but marked differences concerning serum coverage and the content of bone marrow, fibrous tissue and bone cells. These variations resulted in a decreased biofilm density on fresh and fresh-frozen bone grafts after $24 \mathrm{~h}$, despite an increased early biofilm formation and might also be responsible for the variations in colony morphology (small colonies). Detection of small colony variants by microcalorimetry might be a new approach to improve the understanding of biofilm formation.
\end{abstract}

Keywords: Biofilms; Staphylococcus aureus; bone grafts; bacterial colonies.

*Address for correspondence:

Martin Clauss M.D.

Clinic for Orthopaedic and Trauma Surgery

Kantonsspital Baselland Liestal

Rheinstrasse 26

CH-4410 Liestal, Switzerland

Telephone Number: 41619252525

FAX Number : +41 619252808

Email: martin.clauss@ksli.ch

\section{Introduction}

Bone defects are a frequent problem in every day clinical work (Tadic and Epple, 2004). Bone grafts are increasingly used to fill bone defects in orthopaedic and trauma surgery (Ketonis et al., 2010). Autologous cancellous bone grafts are typically harvested from the iliac crest or the distal radius and transplanted as fresh bone grafts during the same operation (De Long et al., 2007). Alternatively, allogeneic cancellous bone grafts can be harvested from femoral heads during primary hip replacement surgery and stored as fresh-frozen bone grafts in a bone bank (Van de Pol et al., 2007; Kappe et al., 2009). Another strategy to fill bone defects is the use of processed cancellous bone grafts (human or bovine) or synthetic/artificial bone grafts such as $\beta$-tricalcium phosphate ( $\beta$-TCP) or hydroxyapatite (HA) (Bohner, 2010).

For structured allogenic bone grafts, mainly used in reconstructive procedures after removal of a bone tumour, bone graft infection is a frequent complication with reported infection rates up to $12 \%$ (Lord et al., 1988; Aro and Aho, 1993). The infection rates of unstructured bone grafts to our knowledge are unknown.

Bone grafts represent a temporary foreign body lacking vascularisation and are therefore of increased susceptibility to infection, which may be introduced either intraoperatively or after surgery by contiguous route. Infections may occur despite proper surgical site preparation and systemic perioperative antimicrobial prophylaxis (Trampuz and Zimmerli, 2006a). In elective orthopaedic surgery, infection rates are reported between 0.7-4.2 \% (Crockarell et al., 1998), whereas they may increase up to $30 \%$ after open fractures (Ostermann et $a l ., 1994)$. Bone grafts with a low propensity for biofilm formation should therefore lead to superior clinical results especially in cases where infection rates are high. The majority of infections associated with orthopaedic foreign bodies are caused by staphylococci (70-90 \%) (Gristina, 1987; Trampuz and Zimmerli, 2006b; Trampuz and Zimmerli, 2008).

Bone graft-associated infections are due to biofilm formation on the surface of the bone graft (Costerton et al., 2005; Trampuz and Zimmerli, 2006b) and often require removal of the infected bone graft with substantial patient morbidity (Zimmerli et al., 2004; Ketonis et al., 2010).

Biofilms are currently one of the main topics in biomaterial and orthopaedic infection research. With regard to pathogenesis, biofilm development is a multistep process including (i) early biofilm formation within $3 \mathrm{~h}$ and (ii) the development of a mature biofilm after $24 \mathrm{~h}$ containing of an additional extracellular matrix (slime 
envelope) with nutrition channels and quorum sensing communication (An and Friedman, 1998; MacKintosh et al., 2006; Patel et al., 2007). Infections associated with biofilms on foreign material are more difficult to treat than the ones caused by bacteria growing in free-living (planktonic) form and eradication is often only possible by removal of the foreign body and long-term antimicrobial treatment (Ehrlich et al., 2005; Ketonis et al., 2010).

Whereas infection of bone grafts is a well-recognised complication, the particular risks and infection dynamics associated with either fresh, fresh-frozen or processed human or bovine cancellous bone grafts are unknown. Aim of this study was a quantitative and qualitative analysis of the formation of (i) early biofilm after $3 \mathrm{~h}$ of incubation and (ii) mature biofilm after $24 \mathrm{~h}$ using a standard laboratory strain of Staphylococcus aureus (ATCC 29213) on the surface of (i) fresh and (ii) fresh-frozen human bone grafts out of femoral heads and commercially available cancellous bone grafts of processed (iii) human or (iv) bovine bone.

\section{Materials and Methods}

The study protocol regarding sampling of human cancellous bone grafts was approved by the institutional review board (EKBB 79/09). Donors of femoral heads gave informed consent prior to surgery.

As donors, we included two otherwise healthy male patients (77 and 73 years of age) who were scheduled for total hip replacement (THR) due to primary coxarthritis without any lifetime history of bacterial coxitis and a one year history without bacterial infection due to $S$. aureus. Antibiotic prophylaxis was postponed until harvesting of the femoral heads, in order to avoid a carryover of antibiotics that might have interfered with biofilm formation. Afterwards, the patients received a single shot of Cefuroxime $1.5 \mathrm{~g}$ (Sandoz, Basel, Switzerland) and the implantation of the THR was continued without any further modifications of the routine setting. Both patients had an uneventful wound healing and postoperative rehabilitation.

\section{Bone graft samples}

Fresh (fr) human cancellous bone grafts were harvested as cylinders $(6.5 \times 10 \mathrm{~mm})$ out of femoral heads during total hip replacement in the operating room using a hollow drill system (SDS, Zimmer, Winterthur, Switzerland). Perioperative antibiotic prophylaxis was postponed until the femoral head was harvested. Afterwards, processed samples were transferred to $10 \mathrm{~mL}$ Falcon tubes pre-filled with $1 \%$ phosphate buffered saline (PBS). Samples were transferred to the laboratory and experiments started within $2 \mathrm{~h}$.

Fresh-frozen (ff) human cancellous bone grafts were harvested out of the same femoral head in the same way as fr cylinders, but samples were transferred to sterile Eppendorf tubes and immediately deep-frozen at $-80^{\circ} \mathrm{C}$ in the in-house bone bank. After a storage period of 10 days, samples were transferred deep-frozen to the laboratory, thawed within the Eppendorf tubes filled with $2 \mathrm{~mL}$ of $1 \%$
PBS at room temperature and processed within 2 hours.

Processed human ( $\mathrm{ph}$ ) cancellous bone grafts (Tutoplast $^{\mathrm{TM}}$, Novomedics, Zürich, Switzerland) were obtained as ready-to-use cylinders $(6.5 \times 10 \mathrm{~mm})$ from the manufacturer. Tutoplast ${ }^{\mathrm{TM}}$ is a commercially available human bone graft material processed through a multi-step chemical treatment (osmolysis, $\mathrm{NaOH}, \mathrm{H}_{2} \mathrm{O}_{2}$, and acetone) to obtain a sterile product (Tadic and Epple, 2004). After processing samples consist of almost $45 \mathrm{wt} \%$ of carbonated $\mathrm{HA}, 9 \mathrm{wt} \% \mathrm{H}_{2} \mathrm{O}$ and $34 \mathrm{wt} \%$ of soft tissue and organic bone matrix (BM) (Tadic and Epple, 2004).

Processed bovine (pb) cancellous bone grafts (Tutobone $^{\mathrm{TM}}$, Novomedics, Zürich, Switzerland) were obtained in the same shape as ph and are produced in the same way as mentioned above but out of bovine bone. Final samples contain a higher percentage of $\mathrm{HA}(57 \mathrm{wt} \%)$ and less soft tissue and organic BM (26 wt \%) as compared to ph blocks (Tadic and Epple, 2004).

\section{Bacterial strains}

S. aureus ATCC 29213 (a methicillin-susceptible strain) was used in all experiments. This strain represents a commonly used laboratory reference strain for investigation of biofilms (Ceri et al., 1999). The strain was stored at $-70^{\circ} \mathrm{C}$ by using a cryovial bead preservation system (Microbank, Por.Lab Diagnostics, Richmond Hill, Ontario, Canada). For preparation of the inoculum, a single bead was grown on sheep blood agar overnight. Bacterial stock solution was prepared from individual colonies which were resuspended in $1 \%$ PBS to a McFarland turbidity of 0.5 representing a bacterial concentration of about $1 \times 10^{8}$ colony-forming units $(\mathrm{cfu}) / \mathrm{mL}$, which was diluted 1:100 for further experiments.

\section{Biofilm formation}

$50 \mathrm{~mL}$ Falcon tubes were pre-filled with $2700 \mu \mathrm{L}$ tryptic soy broth (TSB, Becton Dickinson, Basel, Switzerland). Five replicates of each test material were placed separately onto the surface of the broth with a sterile forceps to allow a homogeneous soaking of the porous blocks over $30 \mathrm{~min}$ (Stahli et al., 2010). At the end of the period, samples were completely submerged due to the additional water content in the pores. Then $300 \mu \mathrm{L}$ of bacterial stock solution were added to the media. One set of 5 samples was incubated at $37^{\circ} \mathrm{C}$ in ambient air under static conditions for $3 \mathrm{~h}$, and another set of 5 samples for $24 \mathrm{~h}$.

\section{Biofilm analysis}

Sonication

After either $3 \mathrm{~h}$ (early biofilm) or $24 \mathrm{~h}$ (mature biofilm) incubation, samples were transferred with a sterile forceps to a new $50 \mathrm{~mL}$ Falcon tube and washed 3 times with $5 \mathrm{~mL}$ of $1 \%$ PBS. Afterwards samples were vortexed (Vortex Genie 2, Scientific Industries, Bohemia, NY, USA) for $10 \mathrm{~s}$ at maximum power, sonicated in a bath tub type sonicator (BactoSonic, Bandelin, Berlin, Germany) at $40 \mathrm{kHz}$ and acoustic power of $0.2 \mathrm{~W} / \mathrm{cm}^{2}$ for $5 \mathrm{~min}$ and vortexed again for $10 \mathrm{~s}$ (Trampuz et al., 2007a) with the samples completely immersed. Sonication fluid was transferred to a $10 \mathrm{~mL}$ Falcon tube and the samples harvested for further investigation. 


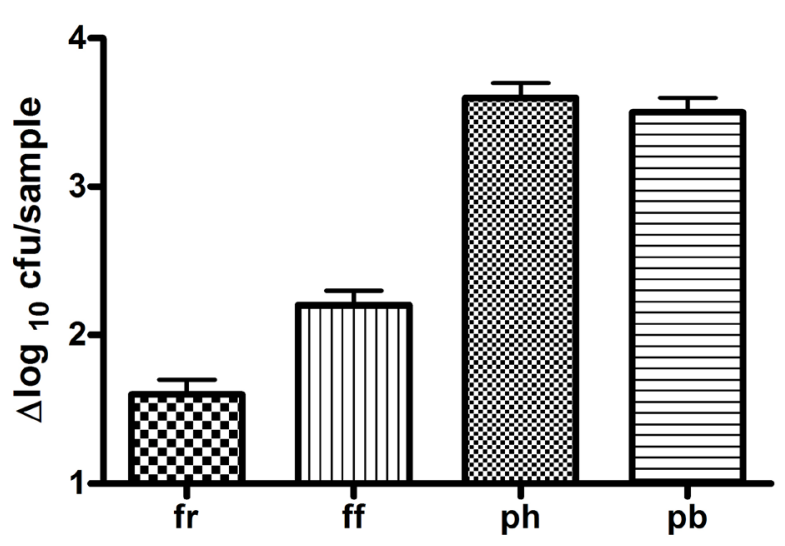

Fig. 1. Evaluation of bacterial density in sonication fluid. Change in bacterial density $\left(\Delta \log _{10} \mathrm{cfu} / \mathrm{sample} \pm \mathrm{SD}\right)$ on the surface of fr, ff, ph and pb bone grafts. Differences between all groups are significant $(p<0.001)$ except between $\mathrm{ph}$ and $\mathrm{pb}(p>0.05)$

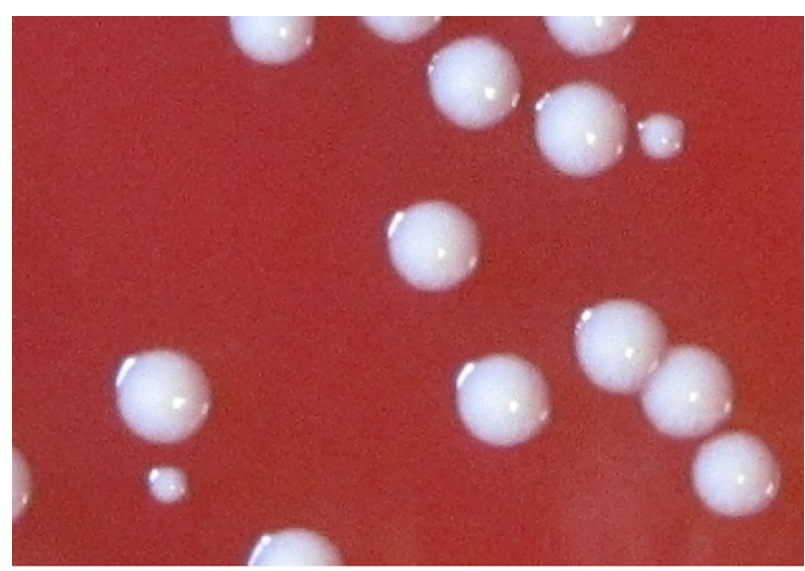

Fig. 2. Differences in colony morphology growing from sonication fluid (representative area).
The dislodged biofilm (sonication fluid) was serially diluted in Eppendorf tubes and aliquots of $100 \mu \mathrm{L}$ were plated on sheep blood agar and incubated at $37^{\circ} \mathrm{C}$ aerobically for $24 \mathrm{~h}$. Bacterial counts were enumerated and expressed as cfu/sample. Differences in colony counts between the $3 \mathrm{~h}$ and $24 \mathrm{~h}$ incubations were calculated.

Plates were examined for variations in colony morphology (colour, size). Colonies of different sizes were Gram stained to assess the presence of Gram-positive cocci and re-plated on blood agar (incubated at $37^{\circ} \mathrm{C}$ with ambient air for $24 \mathrm{~h}$ ) for further analysis. Colonies with different size were further analysed by microcalorimetry (see below).

\section{Microcalorimetry}

After sonication, test samples were transferred with a sterile forceps into microcalorimeter glass ampoules pre-filled with $1 \mathrm{~mL}$ TSB. Ampoules were sealed with rubber cups and transferred into the microcalorimeter to analyse the remaining biofilm (Clauss et al., 2010). Heat was measured in a 48-channel batch microcalorimeter (thermal activity monitor, model 3102 TAM III; TA Instruments, New Castle, DE, USA) at $37 \pm 0.0001{ }^{\circ} \mathrm{C}$ with a sensitivity of $200 \mathrm{nW}$. Heat was measured every $10 \mathrm{~s}$ and expressed as heat-flow over time (in microwatts $[\mu \mathrm{W}]$ ). Calorimetric time to detection (TTD) was defined as the time from insertion of the ampoule into the calorimeter to an exponentially rising heat-flow signal exceeding $100 \mu \mathrm{W}$. Choosing the detection limit at $100 \mu \mathrm{W}$ ensures that only replicating bacteria are detected. TTD indirectly quantifies the amount of bacteria with a shorter TTD representing a higher amount of bacteria. Quantitative differences in bacterial load ( $\Delta T T D)$ between the mature and early biofilm were calculated.

The theoretical detection limit of the microcalorimetric assay is one viable cfu/mL (Trampuz et al., 2007b). The peak heat-flow (PHF) was defined as the maximum heatflow after an exponential rise of the signal and the time to reach the peak heat-flow (ttPHF) was recorded. Whenever multiple peaks were recorded during the experiment they were enumerated sequentially (PHF1, PHF2) and the different time intervals to reach peak heat-flow (ttPHF) recorded. The total produced heat (TPH, in joules $[\mathrm{J}]$ ) was determined by integration of the area below the heat-flowtime curve from time 0 until $24 \mathrm{~h}$ (Trampuz et al., 2007c).

Colonies with different morphology assessed after plating of the dislodged biofilm (sonication fluid) were resuspended in $1 \%$ PBS to a McFarland turbidity of 0.5 and $50 \mu \mathrm{L}$ transferred in microcalorimetry ampoules containing $2 \mathrm{~mL}$ fresh TSB to investigate potential differences in bacterial metabolism.

\section{Statistical analysis}

All experiments were performed in sets of five to calculate the mean \pm standard deviation. Statistical analysis was done by Kruskal-Wallis test with Dunn's multiple comparison tests using Prism 5.0 (GraphPad Software, La Jolla, CA, USA). The significance level was set at $\alpha=0.05$ and a $p$-value of $<0.05$ was considered significant.

\section{Results}

\section{Sonication (detecting dislodged biofilm)}

After $3 \mathrm{~h}$ incubation (early biofilm), bacterial counts in the sonication fluid $\left(\log _{10} \mathrm{cfu} / \mathrm{sample}\right)$ were highest on the ff bone grafts $(5.5 \pm 0.3)$ compared to fr $(5.1 \pm 0.3$, $p>0.05)$, ph $(4.0 \pm 0.3, p<0.01)$ and $\mathrm{pb}(4.5 \pm 0.2$, $p<0.01)$ bone grafts. Bacterial counts ( $\log _{10} \mathrm{cfu} /$ sample) after $24 \mathrm{~h}$ (mature biofilm) were lowest on the fr bone grafts $(6.7 \pm 0.2, p<0.01)$ but no difference between the 3 other groups was observed (ff $7.8 \pm 0.2$, ph $7.6 \pm 0.2$, pb $8.0 \pm 0.4 ; p>0.05)$. The lowest increase in bacterial density $\left(\Delta \log _{10} \mathrm{cfu} /\right.$ sample) between early and mature biofilm was detected on fr bone grafts $(1.6 \pm 0.1, p<0.001$, Fig. 1). The plating of the $\mathrm{ph}$ and $\mathrm{pb}$ bone grafts on agar plates showed identical $S$. aureus colony morphologies. In contrast, colonies with 2 different diameters (small and large) were found on the plates of the fr (early biofilm 
a

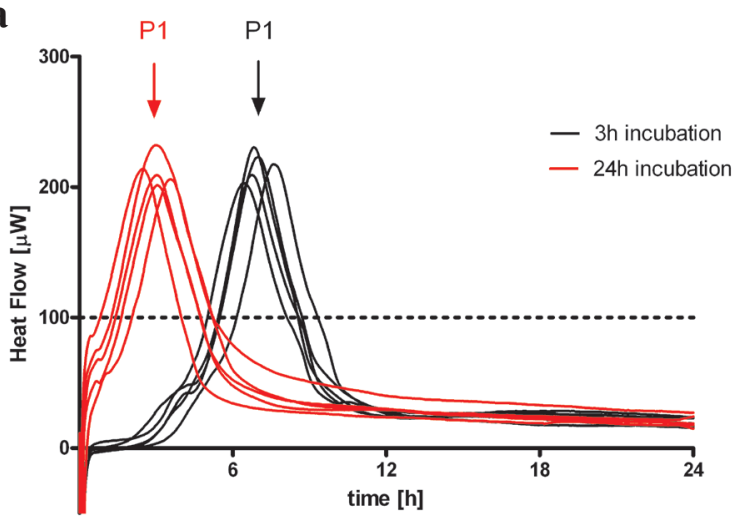

c

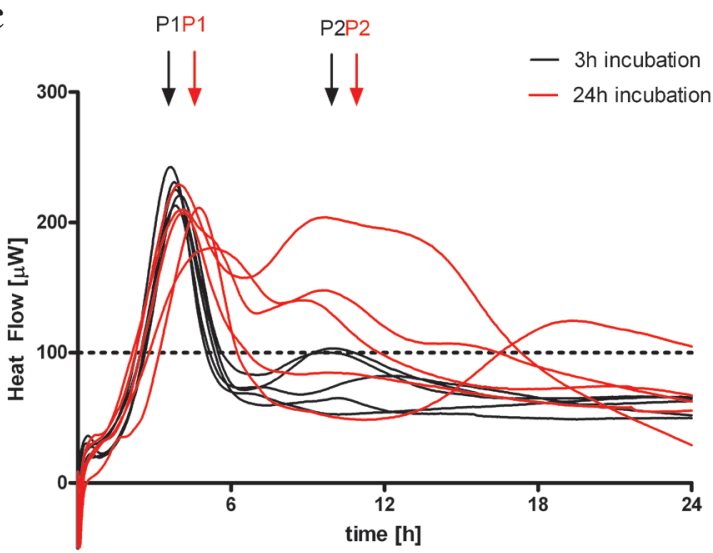

b

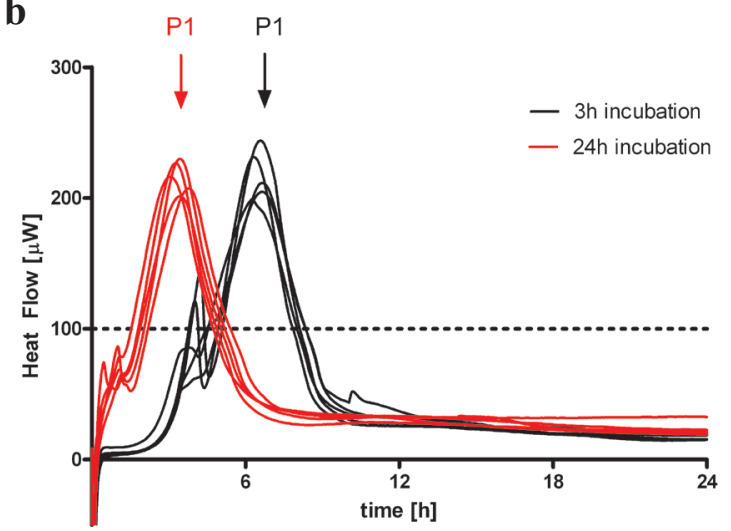

d

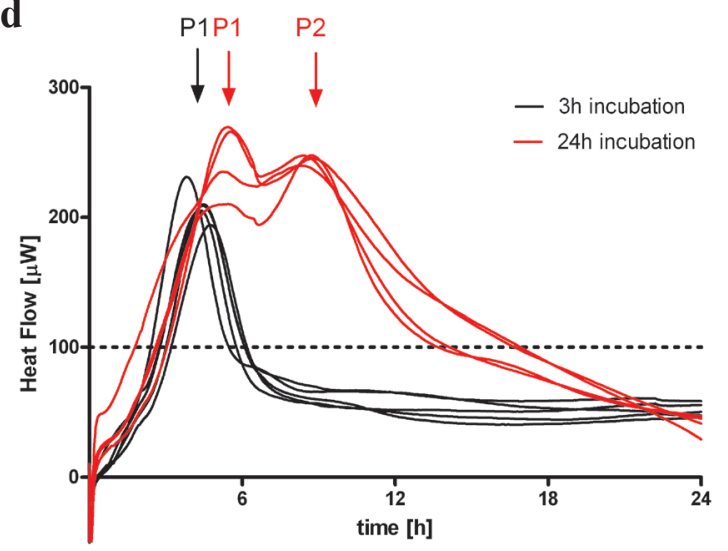

Fig. 3. Heat-flow curves for: (a) processed human (ph), (b) processed bovine (pb), (c) fresh (fr), (d) fresh-frozen (ff) bone grafts. P1 and P2 represent calculated peak number 1 and 2 out of all curves (Table 1). Heat-flow curves show a batch signal of heat produced in the ampoules. The initial thermal equilibration of the ampoules (negative values within the first $15 \mathrm{~min}$ ) is followed by an exponentially rising signal in the ampoules, reflecting exponential growth of the bacteria. After depletion of nutrient inside the ampoules (PHF) the signal turns and shows a negative slope.

and mature biofilm) and ff bone grafts (mature biofilm, Fig. 2). Gram staining showed a homogeneous pattern of Gram-positive cocci (data not shown). After re-plating, all colonies reverted to large colonies of $S$. aureus only.

\section{Microcalorimetry (remaining biofilm)}

The microcalorimetric analysis of the remaining biofilm after sonication showed two different shapes of heat-flow curves. The ph (Fig. 3a) and pb (Fig. 3b) bone grafts had one single peak exceeding $100 \mu \mathrm{W}$ for early biofilm as well as for the mature biofilm. The fr bone grafts (Fig. 3c) had a double peak for each of the two investigated time points. One peak was found for the ff bone grafts after $3 \mathrm{~h}$ incubation (early biofilm), while two peaks were observed analysing the remaining mature biofilm after $24 \mathrm{~h}$ incubation (Fig. 3d). The highest number of bacteria (shortest TTD) in the remaining mature biofilm ( $24 \mathrm{~h}$ incubation) was found on the surface of the ph and $\mathrm{pb}$ bone grafts. A lower number of bacteria (i.e., longer TTD) was found on the surface of fr and ff bone grafts incubated for $3 \mathrm{~h}(p<0.05)$ and $24 \mathrm{~h}(p<0.05)$ with no differences in bacterial density between fr and ff bone grafts $(p>0.05)$ independent of whether incubated for $3 \mathrm{~h}$ or $24 \mathrm{~h}(p>0.05)$. The lowest number of bacteria (longest TTD, $p<0.01$ ) was found on the ph and pb bone grafts incubated for $3 \mathrm{~h}$. Microcalorimetric results (remaining biofilm) corresponded well with the quantitative cultures of the removed biofilm after sonication and plating (Fig. $1)$. The quantitative increase in bacterial density ( $\triangle T T D)$ on the surface of the samples was $3.9 \pm 0.2 \mathrm{~h}(p<0.001)$ for ph and $2.9 \pm 0.1 \mathrm{~h}(p<0.001)$ for pb, respectively. fr $(0.1 \pm 0.2 \mathrm{~h}, p>0.05)$ and $\mathrm{ff}(0.1 \pm 0.4 \mathrm{~h}, p>0.05)$ showed no $\triangle \mathrm{TTD}$, but an additional second peak reflecting an additional number of bacteria (Table 1, Fig. 3c,d). These findings corresponded well with the increase in bacterial counts from the removed biofilm in sonication fluid (Fig. $1)$.

PHF of the first peak was independent of the length of incubation and the test material and reached an average of $219 \pm 20 \mathrm{~J}(p>0.05)$. PHF is directly related to the detected germ, thus potential contaminations in the ampoules can be excluded. A second peak was only seen in ff and fr, it was higher on $\mathrm{ff}$ than on fr bone grafts $(p<0.01$, Table 1$)$. After $3 \mathrm{~h}$ incubation there were no differences $(p>0.05)$ in the total produced heat (TPH) comparing fr and ff bone grafts but between fr and ph $(p<0.05)$ and between fr and 
$\mathrm{pb}(p<0.05)$. TPH was highest on $\mathrm{ff}$ bone grafts incubated for $24 \mathrm{~h}$ (Table 1) and TPH was higher compared to fr $(p>0.05), \mathrm{pb}(p<0.05)$, and $\mathrm{pb}(p<0.01)$ bone grafts.

Microcalorimetric analysis of resuspended (planktonic) bacteria of different colony morphology showed a delayed heat-flow curve with a decreased peak heat-flow for the small colonies compared to the heat-flow curves of normal sized colonies (Fig. 4). The time points for the ttPHF in Fig. 4 are matching with the ttPHF in Fig. $3 \mathrm{c}$ and $\mathrm{d}$ for both the small and large cfu. The increased height of the curves in Fig. 4 is due to the fact that the planktonic (resuspended) bacteria are metabolically more active than their biofilm counterparts. In summary, we found the largest increase in biofilm density from $3 \mathrm{~h}$ incubation to $24 \mathrm{~h}$ incubation was observed on the surface of $\mathrm{ph}$ and $\mathrm{pb}$ bone grafts both by sonication and microcalorimetry. After $24 \mathrm{~h}$ incubation the absolute amount of biofilm was also highest on ph and $\mathrm{pb}$ grafts. Small colonies found in the sonication fluid of fr and ff grafts were also detected by microcalorimetry (expressed by the double peak of the heat-flow curve).

\section{Discussion}

Biofilm formation is a multi-step process (Gristina, 1987; An and Friedman, 1998) and extensive research on medical devices and their propensity for biofilm formation by staphylococci has been performed during the last years (Harris and Richards, 2006). Several factors, such as surface hydrophobicity (Jakubowski et al., 2008), surface charge (Oga et al., 1988), surface roughness (Harris et $a l ., 2007)$ and surface chemistry (Abraham and Jefferson, 2010; MacKintosh et al., 2006; Patel et al., 2003; Patel et al., 2007) have been shown to influence biofilm formation. But the effect of these findings on bone grafts in clinical practice is unclear and the use of fresh autologous bone grafts is still regarded the standard procedure to fill bone defects (Delloye et al., 2007; De Long et al., 2007; Ketonis et al., 2010).

To our knowledge, there are no data comparing the formation of early and mature biofilm on the surface of

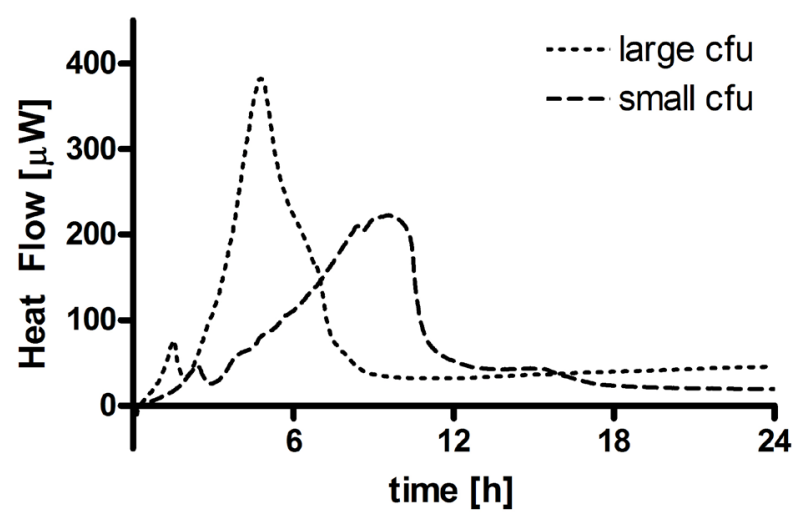

Fig. 4. Microcalorimetric analysis of resuspended (planktonic) bacterial colonies with two different morphologies.

fresh (fr), fresh-frozen (ff) or processed human (ph) and bovine $(\mathrm{pb})$ cancellous bone grafts. The aim of our study was to quantitatively and qualitatively evaluate (i) the early biofilm within $3 \mathrm{~h}$ and (ii) the mature biofilm within $24 \mathrm{~h}$ of $S$. aureus (ATCC 29213) on fr, ff, ph and pb bone grafts under standardised in vitro conditions.

The fr, ff and ph bone grafts are harvested out of human femoral heads and thus have the same architecture of the CaP skeleton. The pb bone grafts differ by means of the $\mathrm{CaP}$ content which is slightly higher in the bovine samples (Tadic and Epple, 2004). Despite these minor structural differences, the four investigated materials harbour marked differences. The surfaces of fr and ff bone grafts are covered by serum proteins, whereas proteins are completely removed during processing in $\mathrm{ph}$ and $\mathrm{pb}$ bone grafts (information from manufacturer). There are only minor differences in the composition of serum proteins but a reduced content of water in the ff bone grafts compared to the fr bone grafts, due to freezing and storage at $-80{ }^{\circ} \mathrm{C}$ (Nade, 2002). Additionally, fr and $\mathrm{ff}$ bone grafts are partly filled with bone marrow containing granulocytes, fibroblasts and connective fibrous tissue, which is not present in the ph and pb bone grafts. It is

Table 1: Microcalorimetric evaluation of biofilm formation on the different bone grafts. Data represent sets of five samples and are presented as mean \pm SD. Time to detection (TTD) was measured at $100 \mu \mathrm{W}$. Peak heat-flow (PHF) reflects the peaks of the heat-flow curve after an exponential rise of the signal and time-to-PHF (ttPHF) the time period until PHF was reached. Peaks are enumerated sequentially in case of multiple peaks (Fig 3a-d). Total produced heat (TPH) represents the total amount of energy produced during the $24 \mathrm{~h}$ interval and is calculated by integrating the area under the heat-flow curve.

\begin{tabular}{|c|c|c|c|c|c|c|c|}
\hline $\begin{array}{c}\text { incubation } \\
\text { time }\end{array}$ & Sample & TTD [h] & PHF $1[\mu W]$ & ttPHF $1[\mathrm{~h}]$ & PHF $2[\mu W]$ & ttPHF 2 [h] & ТРН [J] \\
\hline \multirow{4}{*}{$m \stackrel{0}{\stackrel{a}{\Xi}}$} & $f r$ & $2.5 \pm 0.2$ & $226.3 \pm 10.0$ & $3.8 \pm 0.1$ & $83.2 \pm 16.1$ & $13.3 \pm 5.5$ & $6.6 \pm 0.5$ \\
\hline & $f f$ & $2.8 \pm 0.3$ & $209.8 \pm 12.0$ & $4.4 \pm 0.3$ & - & - & $5.8 \pm 0.5$ \\
\hline & $p h$ & $5.5 \pm 0.4$ & $216.5 \pm 9.7$ & $6.9 \pm 0.4$ & - & - & $3.8 \pm 0.2$ \\
\hline & $p b$ & $4.8 \pm 0.2$ & $218.2 \pm 16.8$ & $6.5 \pm 0.2$ & - & - & $4.1 \pm 0.1$ \\
\hline \multirow{4}{*}{ 志 } & $f r$ & $2.6 \pm 0.4$ & $207.4 \pm 15.6$ & $4.4 \pm 0.5$ & $140.2 \pm 38.6$ & $11.4 \pm 4.0$ & $8.8 \pm 1.7$ \\
\hline & $f f$ & $3.0 \pm 0.9$ & $249.5 \pm 23.5$ & $5.7 \pm 0.5$ & $245.0 \pm 3.2$ & $8.5 \pm 0.2$ & $10.6 \pm 1.1$ \\
\hline & $p h$ & $1.6 \pm 0.3$ & $207.2 \pm 14.3$ & $3.1 \pm 0.2$ & - & - & $4.3 \pm 0.8$ \\
\hline & $p b$ & $1.9 \pm 0.2$ & $216.2 \pm 11.0$ & $3.4 \pm 0.2$ & - & - & $4.3 \pm 0.2$ \\
\hline
\end{tabular}


questionable whether the cells are still viable at the end of the $3 \mathrm{~h}$ incubation in the fr bone grafts setting, but these cells should die during $24 \mathrm{~h}$ incubation (fr bone grafts) or freezing and thawing (ff bone grafts). Bone cells, that are initially present in the fr and ff bone grafts too, die once living bone is separated from its blood supply (Nade, 2002), thus living bone cells are not present in any of the investigated samples.

The use of ultrasound is a standard procedure to dislodge biofilms from devices (Ceri et al., 1999; Monsen et al.,2009) and was adapted to the sample sizes (Clauss et al., 2010) from our recently published protocol (Trampuz et al., 2007a). Our results demonstrate an increased early biofilm formation at $3 \mathrm{~h}$ as shown both by direct CFU counts as well as microcalorimetry experiments on the serum covered surface of $\mathrm{fr}$ and $\mathrm{ff}$ bone grafts but a decrease after $24 \mathrm{~h}$. Abraham and Jefferson (Abraham and Jefferson, 2010) have recently shown that a low molecular weight component of serum inhibits the formation of $S$. aureus biofilms. In contrast, MacKintosh et al. (MacKintosh et al., 2006) and Patel et al. (Patel et al., 2007) found a significant reduction of the early biofilm (2-12 h) but an increased $S$. epidermidis biofilm formation within $24 \mathrm{~h}$ on the surface of polymers. Both studies (MacKintosh et al., 2006; Patel et al., 2007) investigated the effect of various incubation media (human serum, TSB, PBS) on biofilm formation on different surfaces. We only used TSB as growth media to provide the same substrates to the bacteria (An and Friedman, 1998) to focus on the influence of the surface modifications and proteins on biofilm formation.

Analysing colony morphology, we found small colonies of $S$. aureus on the plates of fr ( $3 \mathrm{~h}$ and $24 \mathrm{~h}$ incubation) and ff ( $24 \mathrm{~h}$ incubation) bone grafts but not on the plates of the ph and pb bone grafts. Small colony variants (SCV) represent a subpopulation of naturally occurring, slow growing phenotypes with a distinct pathogenic trait and a colony size of one-tenth of "normal" S. aureus (Von Eiff, 2008; Sendi and Proctor, 2009). A persistence of SCV of $S$. aureus has been documented in lysosomes of living cells showing a great resistance of this life-form in tissue culture models (Schroder et al., 2006) and explaining the difficulties eradicating SCV infections in vivo. Anyhow, an intracellular growth as a potential explanation for the occurrence of SCV in our experimental setting can be excluded because no viable eukaryotic cells are present even on the surface of the fr bone grafts incubated for $3 \mathrm{~h}$ (Nade, 2002). The observed reversion of SCV to a "normal" morphology size is well described (Sendi and Proctor, 2009). Normally, SCV become visible on growth media at least $72 \mathrm{~h}$ after normal-sized colonies (Sendi and Proctor, 2009), unexpectedly we found small colonies within $24 \mathrm{~h}$ after plating.

Microcalorimetry has been shown to be an ideal tool to evaluate biofilm formation (Lerchner et al., 2008; Buchholz et al., 2010; Clauss et al., 2010) and we had two interesting findings: Firstly, we found an expected increase in bacterial density (shorter TTD) in the remaining biofilm with longer incubation for both processed materials (ph and $\mathrm{pb}$ ), but there was no change in the TTD for fr and ff bone grafts comparing $3 \mathrm{~h}$ and $24 \mathrm{~h}$ incubation. TTD correlated well with the cfu counts after sonication, thus these results are not a consequence of different amounts of bacteria being dislodged during the sonication procedure; Secondly, heat-flow curves with two peaks were only seen with fresh ( $3 \mathrm{~h}$ and $24 \mathrm{~h}$ incubation) and fresh-frozen $(24 \mathrm{~h}$ incubation) samples and small colonies were only found for these samples, too. Heat flow curves represent an unspecific sum signal of exothermal and endothermal reactions within the calorimetry ampoules and might be affected by oxygen depletion and accumulation of metabolic waste (Braissant et al., 2010). Our experimental setting provided the same amount of TSB and oxygen to all samples, thus variations in the heat-flow curves should not be related to varying conditions in the ampoules. The microcalorimetric analysis of the two different colony types showed a slower/reduced metabolism (delayed TTD) for the small colonies. The second peak in the heat-flow curves of biofilm analysis seems to be related to the presence of small colonies on these samples. The small colonies might have grown because of the presence of human serum proteins, cells and fibrous tissue on these two non-cleaned and non-processed samples.

We found significant differences for TPH between samples containing small colonies and those which do not. Microcalorimetry gives a sum signal of all endothermal and exothermal reactions in the ampoules. It is well established that SCV are related to a reduced and modified nutrition (Von Eiff, 2008; Sendi and Proctor, 2009), which is described for bacteria growing in biofilm too (Costerton et al., 1999). Therefore, differences between TPH must be attributed to the ability of the bacteria growing in small colonies to use different/additional sources of energy in the TSB. The presence of small colonies and biofilm formation might be interconnected and research in that field might provide further understanding in foreign body infection.

The limitations of this study should be appreciated:

1. Variations in the bone architecture of the samples might have influenced the results to a certain extent. To normalise these variations an important number of samples from different individuals would be necessary. As the perioperative antibiotic prophylaxis prior to harvesting of the femoral heads during total hip replacement was postponed for this study, patients were exposed to an increased risk of perioperative infection (Trampuz and Zimmerli, 2006a), and the number of examined femoral heads had to be kept small. Therefore, all fr and ff samples were taken from the same femoral head limiting the possible variation in architecture. In contrast ph and pb samples were manufactured out of various donors. As the range in the results was small we believe that our results were not affected by these variations in architecture.

2. We only investigated one bacterial strain. S. aureus ATCC 29213 is a reference strain for in vitro biofilm research especially when incubated in TSB for $24 \mathrm{~h}$ (Ceri et al., 1999) but results might differ with other strains.

\section{Clinical implication and outlook}

More than one million patients per year need a bone grafting procedure to repair a bone defect resulting from 
a trauma or a bone disease (Bohner, 2010). Infection rates for elective orthopaedic surgery are up to almost $5 \%$ (Crockarell et al., 1998) and even higher in case of severe trauma, where bone loss also is more common (Ostermann et al., 1994). Thus, more than 50,000 infected bone grafts/ year must be expected. Treatment of infected bone grafts is a time consuming, costly endeavour, and frequently leads to extraction of the graft material (Geurts et al., 2011). During recent years synthetic bone grafts have appeared for specific use in infection treatment (Geurts et al., 2011). Despite extensive research in the field, none of the synthetic bone grafts matches the unique architecture and composition of bone (Delloye et al., 2007).

All 4 investigated bone grafts have almost the same $\mathrm{CaP}$ architecture and results can be compared against fr bone grafts, which still is regarded as the gold standard for bone grafting procedures (Delloye et al., 2007; Bohner, 2010; Ketonis et al., 2010). Even taking into account the limitations of the in vitro setting fr bone grafts seem to represent the gold standard concerning resistance against staphylococcal biofilm formation. But the SCV found on the fr and ff grafts remain a concern.

Further studies are needed confirming our findings in vivo before advocating the use of one of the 4 tested material in clinical cases were the risk of infection is high.

\section{Conclusion}

We found an increased initial bacterial adhesion of $S$. aureus ATCC 29213 on the surface of serum covered fr and $\mathrm{ff}$ bone grafts as compared to ph and pb bone grafts. While there was only a slight increase of bacterial density over time on the surface of fr and ff bone grafts we found a tremendous increase on both the ph and pb bone grafts.

\section{Acknowledgements}

We want to thank S. Gersbach (MSc) for statistical assistance analysing the data. This study was supported by a research grant (E09_0001) from the RMS Foundation, Bettlach, Switzerland and a grant from the Swiss Society for Orthopaedic Surgery (SGO/SSO). Additional funding was obtained for the microcalorimetric analysis from the Swiss National foundation (\#3200B0-112547) and the Gebert Rüf Stiftung. We thank Novomedics $\mathrm{GmbH}$ (Zürich, Switzerland) for providing Tutoplast ${ }^{\mathrm{TM}}$ and Tutobone ${ }^{\mathrm{TM}}$ samples.

Parts of this study have been presented at the $18^{\text {th }}$ EORS meeting 2010, Davos, Switzerland and at the $21^{\text {th }}$ GRIBOI meeting 2011, Boston, USA.

The authors report no competing interests.

\section{References}

Abraham NM, Jefferson KK (2010) A low molecular weight component of serum inhibits biofilm formation in Staphylococcus aureus. Microb Pathog 49: 388-391.

An Y, Friedman RJ (1998) Concise review of mechanisms of bacterial adhesion to biomaterial surfaces. J Biomed Mater Res A 43: 338-348.
Aro HT, Aho AJ (1993) Clinical use of bone allografts. Ann Med 25: 403-412.

Bohner M (2010) Design of ceramic-based cements and putties for bone graft substitution. Eur Cell Mater 20: $1-12$.

Braissant O, Wirz D, Göpfert B, Daniels AU (2010) Use of isothermal microcalorimetry to monitor microbial activities. FEMS 303: 1-8.

BuchholzF, Harms H, Maskow T (2010) Biofilmresearch using calorimetry - a marriage made in heaven? Biotechnol J 5: 1339-1350.

Ceri H, Olson ME, Stremick C, Read RR, Morck D, Buret A(1999) The Calgary biofilm device: New technology for rapid determination of antibiotic susceptibilities of bacterial biofilms. J Clin Microbiol 37: 1771-1776.

Clauss M, Trampuz A, Borens O, Bohner M, Ilchmann $\mathrm{T}$ (2010) Biofilm formation on bone grafts and bone graft substitutes. Comparison of different materials by a standard in vitro test and microcalorimetry. Acta Biomaterialia 6: 3791-3799.

Costerton JW, Stewart PS, Greenberg EP (1999) Bacterial biofilms: A common cause of persistent infections. Science 284: 1318-1322.

Costerton JW, Montanaro L, Arciola CR (2005) Biofilm in implant infections: Its production and regulation. Int $\mathrm{J}$ Artif Organs 28: 1062-1068.

Crockarell JR, Hanssen AD, Osmon DR, Morrey BF (1998) Treatment of infection with debridement and retention of the components following hip arthroplasty. J Bone Joint Surg Am 80: 1306-1313.

De Long WG Jr, Einhorn TA, Koval K, McKee M, Smith W, Sanders R, Watson T (2007) Bone grafts and bone graft substitutes in orthopaedic trauma surgery. A critical analysis. J Bone Joint Surg Am 89: 649-658.

Delloye C, Cornu O, Druez V, Barbier O (2007) Bone allografts: What they can offer and what they cannot. J Bone Joint Surg Br 89: 574-579.

Ehrlich GD, Stoodley P, Kathju S, Zhao Y, McLeod BR, Balaban N, Hu FZ, Sotereanos NG, Costerton JW, Stewart PS, Post JC, Lin Q (2005) Engineering approaches for the detection and control of orthopaedic biofilm infections. Clin Orthop Relat Res 437: 59-66.

Geurts J, Chris Arts JJ, Walenkamp GH (2011) Bone graft substitutes in active or suspected infection. Contraindicated or not? Injury 42 Suppl 2: S82-86.

Gristina AG (1987) Biomaterial-centered infection: Microbial adhesion versus tissue integration. Science 237: 1588-1595.

Harris LG, Richards RG (2006) Staphylococci and implant surfaces: A review. Injury 37 Suppl 2: S3-14.

Harris LG, Meredith DO, Eschbach L, Richards RG (2007) Staphylococcus aureus adhesion to standard microrough and electropolished implant materials. J Mater Sci: Mater Med 18: 1151-1156.

Jakubowski W, Slósarczyk A, Paszkiewicz Z, Szymanski W, Walkowiak B (2008) Bacterial colonisation of bioceramic surfaces. Adv Appl Ceram 107: 217-221.

Kappe T, Cakir B, Mattes T, Reichel H, Flören M (2009) Infections after bone allograft surgery: A prospective study by a hospital bone bank using frozen femoral heads from living donors. Cell Tissue Bank 11: 253-259. 
Ketonis C, Barr S, Adams CS, Hickok NJ, Parvizi J (2010) Bacterial colonization of bone allografts: Establishment and effects of antibiotics. Clin Orthop Relat Res 468: 2113-2121.

Lerchner J, Wolf A, Buchholz F, Mertens F, Neu TR, Harms H, Maskow T (2008) Miniaturized calorimetry a new method for real-time biofilm activity analysis. $\mathrm{J}$ Microbiol Methods 74: 74-81.

Lord CF, Gebhardt MC, Tomford WW, Mankin HJ (1988) Infection in bone allografts. Incidence, nature, and treatment. J Bone Joint Surg Am 70: 369-376.

MacKintosh EE, Patel JD, Marchant RE, Anderson JM (2006) Effects of biomaterial surface chemistry on the adhesion and biofilm formation of Staphylococcus epidermidis in vitro. J Biomed Mater Res A 78: 836-842.

Monsen T, Lövgren E, Widerström M, Wallinder L (2009) In vitro effect of ultrasound on bacteria and suggested protocol for sonication and diagnosis of prosthetic infections. J Clin Microbiol 47: 2496-2501.

Nade S (2002) The replacement of broken, missing, and diseased bone. In: Bone in Clinical Orthopedics (Fackelman GE, ed), Thieme, Stuttgart/New York, pp 379-411.

Oga M, Sugioka Y, Hobgood CD, Gristina AG, Myrvik QN (1988) Surgical biomaterials and differential colonization by Staphylococcus epidermidis. Biomaterials 9: 285-289.

Ostermann PA, Henry SL, Seligson D (1994) Timing of wound closure in severe compound fractures. Orthopedics 17: 397-399.

Patel JD, Ebert M, Stokes K, Ward R, Anderson JM (2003) Inhibition of bacterial and leukocyte adhesion under shear stress conditions by material surface chemistry. J Biomater Sci Polymer Ed 14: 279-295.

Patel JD, Ebert M, Ward R, Anderson JM (2007) S. epidermidis biofilm formation: Effects of biomaterial surface chemistry and serum proteins. J Biomed Mater Res A 80: 742-751.

Schroder A, Kland R, Peschel A, von Eiff C, Aepfelbacher M (2006) Live cell imaging of phagosome maturation in Staphylococcus aureus infected human endothelial cells: Small colony variants are able to survive in lysosomes. Med Microbiol Immunol 195: 185-194.

Sendi P, Proctor RA (2009) Staphylococcus aureus as an intracellular pathogen: The role of small colony variants. Trends Microbiol 17: 54-58.

Stahli C, Bohner M, Bashoor-Zadeh M, Doebelin N, Baroud G (2010) Aqueous impregnation of porous betatricalcium phosphate scaffolds. Acta Biomater 6: 27602772.

Tadic D, Epple M (2004) A thorough physicochemical characterisation of 14 calcium phosphate-based bone substitution materials in comparison to natural bone. Biomaterials 25: 987.

Trampuz A, Zimmerli W (2006a) Antimicrobial agents in orthopaedic surgery: Prophylaxis and treatment. Drugs 66: 1089-1105.

Trampuz A, Zimmerli W (2006b) Diagnosis and treatment of infections associated with fracture-fixation devices. Injury 37 Suppl 2: S59-66.
Trampuz A, Piper KE, Jacobson MJ, Hanssen AD, Unni KK, Osmon DR, Mandrekar JN, Cockerill FR, Steckelberg JM, Greenleaf JF, Patel R (2007a) Sonication of removed hip and knee prostheses for diagnosis of infection. N Engl J Med 357: 654-663.

Trampuz A, Salzmann S, Antheaume J, Daniels AU (2007b) Microcalorimetry: A novel method for detection of microbial contamination in platelet products. Transfusion 47: 1643-1650.

Trampuz A, Steinhuber A, Wittwer M, Leib SL (2007c) Rapid diagnosis of experimental meningitis by bacterial heat production in cerebrospinal fluid. BMC Infect Dis 7: 116.

Trampuz A, Zimmerli W (2008) Diagnosis and treatment of implant-associated septic arthritis and osteomyelitis. Curr Infect Dis Rep 10: 394-403.

Van de Pol GJ, Sturm PD, Van Loon CJ, Verhagen C, Schreurs BW (2007) Microbiological cultures of allografts of the femoral head just before transplantation. J Bone Joint Surg B 89: 1225-1228.

Von EiffC (2008) Staphylococcus aureus small colony variants: A challenge to microbiologists and clinicians. Int J Antimicrob Agents 31: 507-510.

Zimmerli W, Trampuz A, Ochsner PE (2004) Prostheticjoint infections. N Engl J Med 351: 1645-1654.

\section{Discussion with Reviewers}

Reviewer I: What are the clinical implications of the study regarding selection of bone graft in reconstructive surgery? Authors: From the laboratory setting, it is difficult to draw clinical conclusions as biofilm formation was done in TSB. Anyhow, we believe that in cases with a high risk of infection, autologous human bone still represents the gold standard.

Reviewer II: According to the protocol as it is written, it seems unlikely that a $50 \mathrm{~mL}$ tube with $2.7 \mathrm{~mL}$ of TSB would be enough to submerge the bone graft sample. Were the bone grafts submerged in TSB, or were they floating "on the surface of the broth"?

Authors: The experimental setting was optimised and results presented in our previous study (Clauss et al., 2010, text reference). The $50 \mathrm{~mL}$ tubes give enough volume to (i) submerge the samples (see Fig. D1.), (ii) manipulate them with a forceps in the tube without contamination and (iii) to get an ideal position of the tube in the sonicator to obtain an equal amount of energy on all samples. We agree, however, that the setting in a first glance seems somewhat unlikely.

Fig. D1. Example of submerged CaP sample illustrating the experimental setting. $N . B$. the sample shown has the same dimensions, but is another CaP block and the image was not part of this study.

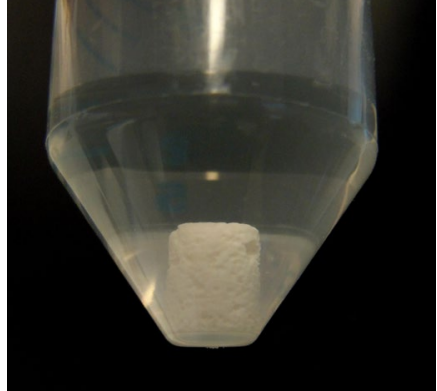

